\title{
PEMANFAATAN HASIL PENGOLAHAN ARSIP STATIS \\ MELALUI LAYANAN AKSES \\ DI DINAS PERPUSTAKAAN DAN KEARSIPAN KABUPATEN SLEMAN
}

\author{
Betty Indriati \\ Dinas Perpustakaan dan Kearsipan Kabupaten Sleman \\ (bettyindriati46@gmail.com)
}

\section{INTISARI}

Arsip statis merupakan arsip yang memiliki nilai guna berkelanjutan. Agar arsip statis dapat berdaya guna bagi masyarakat, maka arsip statis seharusnya tidak hanya disimpan dan dilestarikan, namun harus dimanfaatkan oleh masyarakat untuk berbagai keperluan. Dengan demikian, perlu disusun program layanan akses arsip statis bagi masyarakat. Dengan metode kualitatif melalui pendekatan studi kasus, penelitian ini bermaksud menjabarkan pemanfaatan hasil pengolahan arsip statis melalui layanan akses di Dinas Perpustakaan dan Kearsipan Kabupaten Sleman. Hasil penelitian menunjukkan bahwa program pengolahan dan layanan akses arsip statis di Dinas Perpustakaan dan Kearsipan Kabupaten Sleman dilaksanakan sesuai prosedur operasional standar.

Kata Kunci: arsip statis, pengolahan arsip, layanan akses

\section{ABSTRACT}

Archives have continuing use value. In order for archives to be useful for the community, it should not just be stored and preserved, but must be used by the community for various purposes. Thus, it is necessary to compile an archive access service program for the community. With qualitative methods through a case study approach, this study intends to describe the utilizationof archives processing results through access services in the Dinas Perpustakaan dan Kearsipan Kabupaten Sleman. The results showed that the archival processing and access service program at the Dinas Perpustakaan dan Kearsipan Kabupaten Sleman was carried out according to standard operational procedures.

Keywords: archive, archive processing, access service

\section{PENGANTAR}

\section{Latar Belakang Masalah}

Arsip merupakan salah satu sumber daya organisasi. Berbagai data dan informasi organisasi secara sengaja ataupun tidak akan terekam dalam dokumen berupa arsip. Schwartz dan Cook (2002:19) menyebutkan bahwa memori, seperti sejarah, berakar pada arsip. Tanpa arsip, memori akan terputus-putus, pengetahuan tentang prestasi dan kebanggaan masa lalu akan memudar. Arsip mengatasi menjadi solusi bagi masalah ini. Arsip berisi bukti tentang apa yang terjadi di masa lalu yang tidak mungkin lagi diceritakan secara lisan dan 
turun temurun.

Dalam beberapa waktu terakhir, arsip dan kearsipan menjadi suatu topik yang hangat diperbincangkan di berbagai wilayah di Indonesia. Berbagai seminar tentang kearsipan digelar di berbagai daerah, menjadi sebuah bukti maraknya kajian kearsipan. Hal ini diperkuat dalam dunia pendidikan, yaitu dibukanya program studi kearsipan di beberapa perguruan tinggi. Kearsipan juga dijadikan mata kuliah dalam beberapa bidang studi ilmu administrasi. Selain di dunia pendidikan, muncul pula berbagai komunitas pemerhati kearsipan di tingkat nasional, daerah, dan perguruan tinggi.

Antusisame masyarakat dalam bidang kearsipan tersebut tentu tidak terlepas dari peran pemerintah dalam bidang kearsipan, seperti diterbitkannya undang-undang, peraturan pemerintah, peraturan menteri, hingga peraturan Kepala Arsip Nasional Republik Indonesia terkait dengan kearsipan. Peraturan perundangundangan tersebut kemudian diadopsi oleh lembaga-lembaga kearsipan daerah dan perguruan tinggi dalam rangka penyelenggaraan kearsipan di institusi mereka.

Berbagai peraturan perundang-undangan tersebut diterbitkan bukan saja untuk mengatur mekanisme pengolahan arsip yang lebih banyak berkonsentrasi pada sistem penyimpanan (store) dan pelestarian (preserve), namun juga bertujuan agar arsip yang memiliki nilai guna berkelanjutan dapat berdaya guna bagi masyarakat. Nilai guna berkelanjutan menurut Pearce-Moses (2005:91) adalah kegunaan atau signifikasi jangka panjang suatu arsip yang didasarkan pada nilai guna administrasi, hukum, fiskal, kebuktian, atau historis yang terkandung di dalamnya dan perlu dilestarikan terus-menerus. Dalam undangundang nomor 43 tahun 2009 tentang kearsipan dijelaskan bahwa arsip yang memiliki nilai kesejarahan termasuk dalam kategori arsip statis. Arsip statis adalah arsip yang dihasilkan oleh pencipta arsip karena memiliki nilai guna kesejarahan, telah habis retensinya, dan berketerangan dipermanenkan yang telah diverifikasi baik secara langsung maupun tidak langsung oleh Arsip Nasional Republik Indonesia dan/atau lembaga kearsipan.

\section{Rumusan Masalah}

Dalam rangka penataan arsip serta pendayagunaan arsip bagi masyarakat, maka dirasa perlu untuk menyusun program pengolahan dan layanan akses arsip kepada masyarakat di Dinas Perpustakaan dan Kearsipan Kabupaten Sleman. Selanjutnya menarik untuk diteliti bagaimanakah pemanfaatan hasil pengolahan arsip statis melalui layanan akses arsip statis di Dinas Perpustakan dan Arsip Kabupaten Sleman.

\section{Tujuan Penelitian}

Tujuan penelitian ini adalah untuk mendeskripsikan praktik layanan akses arsip statis di Dinas Perpustakaan dan Kearsipan Kabupaten Sleman dalam rangka pendayagunaan arsip bagi masyarakat.

\section{Metodologi}

Penelitian ini dilakukan dengan metode kualitatif deskriptif dengan pendekatan studi kasus. Nazir (2017:45) menyatakan bahwa studi kasus atau penelitian kasus (case study) adalah penelitian tentang status subjek penelitian yang 
berkenaan dengan suatu fase spesifik atau khas dari keseluruhan personalitas. Cohen, Manion, dan Morisson (2007:253) berpendapat bahwa studi kasus dapat menetapkan sebab dan akibat, dan yang menjadi salah satu kekuatan mereka adalah metode ini mengamati efek dalam konteks nyata. Hitchcock dan Hughes (1995:317) berpendapat bahwa studi kasus memiliki beberapa keunggulan, yaitu: 1) berkenaan dengan deskripsi yang kaya dan jelas mengenai peristiwa yang relevan dengan kasus tersebut; 2) memberikan narasi kronologis peristiwa yang relevan dengan kasus ini; 3) memadukan deskripsi peristiwa dengan analisis mereka; 4) fokusnya pada aktor atau kelompok individu dan berusaha memahami persepsi mereka akan peristiwa; 5) menyoroti secara khusus hal yang relevan untuk kasus ini; 6) Peneliti terlibat secara integral dalam kasus; dan 7) upaya dilakukan untuk menggambarkan kekayaan kasus dalam penulisan laporan. Studi kasus yang dilakukan pada penelitian ini adalah studi pada Dinas Perpustakaan dan Kearsipan Kabupaten Sleman.

Metode pengumpulan data dilakukan melalui wawancara dan observasi. Wawancara dapat dilakukan secara tak berencana dan berfokus; serta dapat pula dilakukan dengan wawancara sambil lalu. Wawancara tak berencana berfokus adalah pertanyaan yang diajukan secara tidak terstruktur namun selalu berpusat pada satu pokok masalah tertentu. Wawancara sambil lalu adalah wawancara yang tertuju pada orang-orang yang dipilih tanpa melalui seleksi terlebih dahulusecara diteliti, tetapi dijumpai secara kebetulan (Koentjaraningrat, 1986) dalam Idrus (2009:104). Sementara itu menurut Idrus
(2009:101), teknik observasi atau pengamatan merupakan aktivitas pencatatan fenomena yang dilakukan secara sistematis. Dalam penelitian ini, wawancara dilakukan terhadap Kepala Dinas Perpustakaan dan kearsipan Kabupaten Sleman dan beberapa arsiparis di tempat tersebut. Adapun observasi dilakukan melalui pengamatan langsung terhadap pelaksanaan layanan akses arsip statis.

Data kemudian disajikan melalui pengorganisasian dan penyajian melalui lima langkah, yaitu: 1) mengamati dalam contoh praktik layanan akses arsip statis telah diorganisir dan disajikan oleh responden; 2) mengatur analisis data dengan individu; 3) mengatur data dengan mempresentasikan semua data yang relevan dengan data layanan arsip; 4) pengorganisasian analisis melalui pertanyaan penelitian; dan 5) mengatur data dengan instrumen.

\section{Kerangka Pemikiran}

Menjadi kewajiban lembaga kearsipan untuk mengolah arsip statis, baik dari hasil akuisisi maupun penyerahan. Pengolahan arsip statis merupakan tahapan pengelolaan arsip agar arsip teratata dan mudah untuk ditemukan kembali. Pengolahan arsip juga bertujuan agar arsip dapat diolah menjadi informasi. Pengolahan arsip didasarkan pada standar deskripsi arsip statis. Standar deskripsi arsip statis merupakan ketentuan dasar dalam mendeskripsikan/merekam informasi arsip statis. Standar deskrispsi arsip statis minimal memenuhi unsur provenance, meliputi nomor arsip, bentuk redaksi, isi ringkas, kurun waktu penciptaan, tingkat perkembangan, jumlah, dan 
kondisi arsip. Hasil akhir pengolahan arsip adalah daftar arsip yang dapat digunakan sebagai sarana temu kembali arsip dari lokasi simpannya. Cook (2013:114) menyatakan bahwa arsip yang memiliki nilai guna permanen akan diserahkan kewenangannya dalam pengelolaan fisik untuk pemrosesan, deskripsi, pelestarian, dan akhirnya menjadi referensi.

Setelah arsip statis diolah, agar arsip statis dapat berdaya guna, maka lembaga kearsipan wajib untuk melaksanakan layanan akses kepada masyarakat. Akses arsip adalah ketersediaan arsip sebagai hasil dari kewenangan hukum dan otorisasi legal serta keberadaan sarana bantu untuk mempermudah penemuan dan pemanfaatan arsip (Undang-undang nomor 43 tahun 2009 tentang Kearsipan). PearceMoses (2005:2) menyatakan bahwa akses adalah: 1) kemampuan untuk menemukan informasi yang relevan melalui penggunaan katalog, indeks, alat temu kembali, atau alat lainnya; 2) izin untuk mencari dan mengambil informasi untuk digunakan sebagai bahan konsultasi atau referensi dari adanya larangan yang ditetapkan secara hukum mengenai privasi, kerahasiaan, dan keamanan; dan 3) pengambilan informasi dari media penyimpanan. Sementara itu menurut Griffin (2009:5), akses adalah hak, kesempatan, atau cara menemukan, menggunakan, atau mengambil informasi.

Dalam kajian kearsipan, pengolahan dan akses arsip berada pada level archives management. Pearce-Moses (2005:33) meyatakan bahwa archives management merupakan pengawasan umum program untuk menilai, memperoleh, mengatur dan mendeskripsikan, melestarikan, mengotentikasi, dan menyediakan akses arsip yang bernilai permanen. Dalam kajian kearsipan di Indonesia, archives management dapat dimaknai dengan istilah pengelolaan arsip statis. Dalam UU nomor 42 tahun 2009 tentang kearsipan disebutkan bahwa pengelolaan arsip statis adalah proses pengendalian arsip statis secara efisien, efektif, dan sistematis meliputi akuisisi, pengolahan, preservasi, pemanfaatan, pendayagunaan, dan pelayanan publik dalam suatu sistem kearsipan nasional.

Dalam Peraturan Pemerintah nomor 28 tahun 2012 tentang Pelaksanaan Undang-undang nomor 43 tahun 2009 tentang Kearsipan pasal 101 dinyatakan bahwa akses arsip statis dilaksanakan dalam rangka pemanfaatan, pendayagunaan, dan pelayanan publik. Maka menjadi tugas arsiparis untuk dapat menyediakan layanan arsip bagi masyarakat. Greene (2009:34) menyatakan bahwa arsiparis seharusnya tidak hanya mengumpulkan dan melestarikan materi dokumenter; tetapi juga harus membuatnya dapat diakses oleh orang lain.

Seperti telah disebutkan di awal, bahwa arsip berisi data dan informasi. Waard dalam laman: https://libraries.mit.edu/ menggambarkan mengenai hirarki data menurut Maslow. Maslow mengambarkan hirarki data melalui tiga level utama, yaitu: 1) saved (preserved and stored); 2) shared (accessible, discoverable, and citable); 3) trusted (comprehensible, reviewed, reproducible, and reusable). Dari gambar tersebut dapat dilihat betapa pengolahan dan pendayagunaan data sebagai informasi cukup penting agar bermanfaat bagi masyarakat. Berikut adalah hirarki data menurut Maslow: 


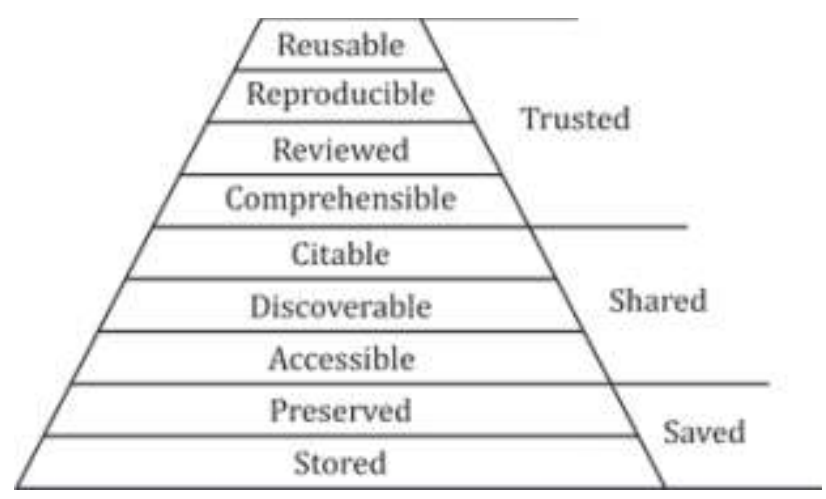

Gambar 1. Hirarki Data Maslow

Sumber: https://libraries.mit.edu/news/maslows-hierarchy-for-data/

Tingginya akses merupakan tujuan utama dikelolanya arsip. Dinas Perpustakaan dan Kearsipan Kabupaten Sleman merupakan salah satu organisasi perangkat daerah yang bertugas menyediakan informasi bagi masyarakat melalui perpustakaan dan kearsipan. Lembaga kearsipan dan perpustakaan, keduanya memiliki user, tetapi dua komunitas tersebut seharusnya memiliki sikap berbeda terhadap user karena holding perpustakaan berbeda dengan kearsipan. Pada umumnya koleksi perpustakaan berupa buku yang tidak terlalu rentan terhadap kerusakan, namun koleksi arsip bersifat lebih unik karena orisinalitasnya. Rhee (2015:37) menyatakan bahwa lembaga kearsipan membatasi layanan kepada pengguna karena dua alasan, yaitu: 1) prioritas pelestarian arsip tradisional dan sumber daya kelembagaan yang terbatas, terutama dalam hal waktu layanan; dan 2) Pelestarian materi fisik membutuhkan banyak waktu dan perhatian dari arsiparis karena material fisik sangat berharga dan bersifat unik. Namun hal itu akan memicu persoalan baru dalam hal ketahanan fisik arsip. Menurut Stewart (2012), pengelola informasi memiliki ketakutan tersendiri ketika membuka koleksi mereka karena rapuhnya beberapa koleksi langka yang telah berusia puluhan tahun.

Sementara itu, di beberapa negara Eropa, lembaga kearsipan, perpustakaan, dan museum berkolaborasi dalam penyedian informasi. Kirchoff, dkk (2008:252) menyatakan bahwa Lembaga Arsip , Perpustakaan dan Museum merupakan institusi memori yang mengatur catatan budaya dan intelektual. Koleksi mereka mengandung memori orang-orang, komunitas, lembaga dan individu, warisan ilmiah dan budaya, dan produk imajiner, kerajinan dan studi. Mereka bergabung dalam rangka penyelamatan warisan budaya. Mereka digunakan oleh anakanak, sarjana, warga negara, oleh orang bisnis, turis dan pelajar. Hal ini pada gilirannya menciptakan warisan masa depan. Memori lembaga memberikan kontribusi langsung maupun tidak langsung untuk kesejahteraan melalui dukungan untuk belajar, perdagangan, pariwisata, dan pemenuhan kebutuhan pribadi.

Dalam hal pemanfaatan arsip, terdapat beberapa arsip yang bersifat open access dan close access. Deliarnoor (2007:5.2) menyatakan bahwa jika suatu arsip boleh dilihat, dipelajari, atau bahkan boleh dipinjam oleh semua orang maka dikatakan arsip tersebut "terbuka". Sedangkan jika arsip tersebut tidak boleh diperlihatkan, dipelajari, dan dipinjam oleh semua orang, kecuali orang yang berhak karena ditunjuk oleh peraturan saja maka dikatakan arsip tersebut "tertutup". Pada dasarnya arsip statis bersifat terbuka, namun dengan pertimbangan tertentu, lembaga arsip dapat menutup akses terhadap suatu arsip, misalnya arsip berisi hal-hal yang rahasia, dapat mengancam kedaulatan negara, atau kasus-kasus yang dapat mengancam kehidupan seseorang. 


\section{PEMBAHASAN}

Profil Kelembagaan Dinas Perpustakaan dan Kearsipan Kabupaten Sleman

Dinas Perpustakaan dan Kearsipan (DPK) Kabupaten Sleman merupakan sebuah instansi pembina perpustakaan dan kearsipan di Kabupaten Sleman yang dibentuk berdasarkan Peraturan Daerah Kabupaten Sleman Nomor 11 Tahun 2016 tentang Pembentukan dan Susunan Perangkat Daerah Pemerintah Kabupaten Sleman dan ditindaklanjuti dengan Peraturan Bupati Sleman Nomor 93 Tahun 2016 tentang Kedudukan, Susunan Organisasi, Tugas Dan Fungsi, Serta Tata Kerja Dinas Perpustakaan dan Kearsipan. Peraturan Daerah tersebut ditetapkan untuk menindaklanjuti Peraturan Pemerintah (PP) Nomor 38 Tahun 2007 tentang Pembagian Urusan Pemerintahan antara Pemerintah, Pemerintahan Daerah Provinsi, dan Pemerintahan Kabupaten/Kota serta Peraturan Pemerintah Republik Indonesia Nomor 18 Tahun 2016 tentang Perangkat Daerah.

Keberadaan Dinas Perpustakaan dan Kearsipan Kabupaten Sleman tidak dapat dilepaskan dari Lembaga Perpustakaan dan Lembaga Kearsipan sebelumnya. Sebelumnya, lembaga ini merupakan dua lembaga yang awalnya berdiri terpisah, namun dalam perkembangannya mengalami beberapa kali perubahan lembaga sesuai dengan aturan dari Pemerintah Pusat yang kemudian pada tahun 2017 disatukan menjadi sebuah Dinas.

Penelitian ini dikhususkan pada lembaga kearsipan daerah. Mengenai sejarah kelembagaannya, pembinaan dan pengelolaan kearsipan pada kurun waktu 1979-1999 merupakan tugas dari Sub Bagian Tata Usaha pada Bagian Umum, Hubungan Masyarakat dan Protokol Sekretariat Wilayah/Daerah Kabupaten Daerah Tingkat II Sleman berdasarkan Peraturan Daerah Nomor 2 Tahun 1979 tentang Susunan Organisasi dan Tatakerja Setwilda Tingkat II Sleman dan Sekretariat Dewan Perwakilan Rakyat Daerah Kabupaten Daerah Tingkat II Sleman. Meskipun Peraturan Daerah tentang Susunan Organisasi Sekretariat Daerah dan Sekretariat DPRD mengalami perubahan, namun tugas pembinaan kearsipan tetap berada pada Sub Bagian Tata Usaha Bagian Umum Sekretariat Daerah sampai dengan tahun 2000.

Penyelenggara Kearsipan daerah sebagai lembaga di Kabupaten Sleman diawali pada Tahun 1999 dengan terbitnya Peraturan Daerah Kabupaten Daerah Tingkat II Sleman Nomor 4 Tahun 1999 tentang Pembentukan Kantor Arsip Daerah Tingkat II Sleman. Seiring berjalannya waktu, lembaga kearsipan mengalami perubahan kelembagaan berdasarkan Peraturan Daerah Nomor 12 Tahun 2000 tentang Organisasi Perangkat Daerah Pemerintah Kabupaten Sleman yang ditindaklanjuti dengan Keputusan Bupati Sleman Nomor 8/Kep.KDH/2001 tentang Struktur Organisasi, Penjabaran Tugas Pokok, dan Fungsi serta Tata Kerja Kantor Data Elektronik, Arsip, dan Perpustakaan.

Sesuai dengan tuntutan kebutuhan organisasi dan kelembagaan, maka perubahan kelembagaan kembali terjadi pada Tahun 2003 dengan terbitnya Peraturan Daerah Kabupaten Sleman Nomor 12 Tahun 2003 tentang Perubahan Pertama Atas Peraturan Daerah Kabupaten Sleman Nomor 12 Tahun 2000 
tentang Organisasi Perangkat Daerah Pemerintah Kabupaten Sleman yang ditindaklanjuti dengan Keputusan Bupati Sleman Nomor 40/Kep.KDH/A/2003 tentang Struktur Organisasi, Penjabaran Tugas Pokok dan Fungsi, serta Tata Kerja Kantor Perpustakaan dan Arsip Daerah.

Terhitung mulai tanggal 1 Januari 2010 lembaga kearsipan di Kabupaten Sleman menjadi Kantor Arsip Daerah Kabupaten Sleman berdasarkan Peraturan Daerah Pemerintah Daerah Kabupaten Sleman Nomor 9 Tahun 2009 tentang Organisasi Perangkat Daerah Pemerintah Kabupaten Sleman yang selanjutnya ditindaklanjuti dengan Peraturan Bupati Sleman Nomor 46 Tahun 2009 tentang Uraian Tugas, Fungsi dan Tata Kerja Kantor Arsip Daerah.

Selanjutnya berdasarkan Peraturan Daerah Kabupaten Sleman Nomor 11 Tahun 2016 tentang Pembentukan dan Susunan Perangkat Daerah Pemerintah Kabupaten Sleman maka Kantor Perpustakaan Daerah dan Kantor Arsip Daerah digabung menjadi satu dengan nama Dinas Perpustakaan dan Kearsipan Kabupaten Sleman yang ketugasannya diatur dalam Peraturan Bupati Sleman Nomor 93 Tahun 2016 tentang Kedudukan, Susunan Organisasi Tugas dan Fungsi, serta Tata Kerja Dinas Perpustakaan dan Kearsipan. Dinas Perpustakaan dan Kearsipan Kabupaten Sleman mulai melaksanakan ketugasannya mulai 2 Januari 2017 hingga saat ini.

Apabila disederhanakan, perubahan kelembagaan Dinas Perpustakaan dan Kearsipan Kabupaten Sleman adalah sebagai berikut:

\begin{tabular}{|c|c|c|}
\hline Tahun & $\begin{array}{l}\text { Kedudukan/Nama } \\
\text { Lembaga }\end{array}$ & Dasar Pembentukan dan Pelaksanaan Tugas \\
\hline 1979-1999 & $\begin{array}{l}\text { Sub Bagian Tata } \\
\text { Usaha pada Bagian } \\
\text { Umum, Hubungan } \\
\text { Masyarakat dan } \\
\text { Protokol Sekretariat } \\
\text { Wilayah/Daerah } \\
\text { Kabupaten Daerah } \\
\text { Tingkat II Sleman }\end{array}$ & $\begin{array}{l}\text { Peraturan Daerah Nomor } 2 \text { Tahun } 1979 \\
\text { tentang Susunan Organisasi dan Tatakerja } \\
\text { Setwilda Tingkat II Sleman dan Sekretariat } \\
\text { Dewan Perwakilan Rakyat Daerah } \\
\text { Kabupaten Daerah Tingkat II Sleman. }\end{array}$ \\
\hline $1999-2000$ & $\begin{array}{l}\text { Kantor Arsip Daerah } \\
\text { Tingkat II Sleman }\end{array}$ & $\begin{array}{l}\text { Peraturan Daerah Kabupaten Daerah } \\
\text { Tingkat II Sleman Nomor } 4 \text { Tahun } 1999 \\
\text { tentang Pembentukan Kantor Arsip Daerah } \\
\text { Tingkat II Sleman. }\end{array}$ \\
\hline $2000-2010$ & $\begin{array}{l}\text { Kantor Data } \\
\text { Elektronik, Arsip, dan } \\
\text { Perpustakaan }\end{array}$ & $\begin{array}{l}\text { Peraturan Daerah Nomor } 12 \text { Tahun } 2000 \\
\text { tentang Organisasi Perangkat Daerah } \\
\text { Pemerintah Kabupaten Sleman, Keputusan } \\
\text { Bupati Sleman Nomor } 8 / \text { Kep.KDH/2001 } \\
\text { tentang Struktur Organisasi, Penjabaran } \\
\text { Tugas Pokok, dan Fungsi serta Tata Kerja } \\
\text { Kantor Data Elektronik, Arsip, dan } \\
\text { Perpustakaan }\end{array}$ \\
\hline $2010-2017$ & $\begin{array}{l}\text { Kantor Arsip Daerah } \\
\text { Kabupaten Sleman }\end{array}$ & $\begin{array}{l}\text { Peraturan Daerah Pemerintah Daerah } \\
\text { Kabupaten Sleman Nomor } 9 \text { Tahun } 2009 \\
\text { tentang Organisasi Perangkat Daerah } \\
\text { Pemerintah Kabupaten Sleman; Peraturan } \\
\text { Bupati Sleman Nomor 46 Tahun } 2009 \\
\text { tentang Uraian Tugas, Fungsi dan Tata } \\
\text { Kerja Kantor Arsip Daerah. }\end{array}$ \\
\hline $\begin{array}{l}2017- \\
\text { sekarang }\end{array}$ & $\begin{array}{l}\text { Dinas Perpustakaan } \\
\text { dan Kearsipan } \\
\text { Kabupaten Sleman }\end{array}$ & $\begin{array}{l}\text { Peraturan Daerah Kabupaten Sleman } \\
\text { Nomor } 11 \text { Tahun } 2016 \text { tentang } \\
\text { Pembentukan dan Susunan Perangkat } \\
\text { Daerah Pemerintah Kabupaten Sleman; } \\
\text { Peraturan Bupati Sleman Nomor } 93 \text { Tahun } \\
2016 \text { tentang Kedudukan, Susunan } \\
\text { Organisasi Tugas dan Fungsi, serta Tata } \\
\text { Kerja Dinas Perpustakaan dan Kearsipan }\end{array}$ \\
\hline
\end{tabular}

\section{Tugas Dan Fungsi Organisasi}

Berdasarkan Peraturan Bupati Sleman Nomor 93 Tahun 2016 tentang Kedudukan, Susunan Organisasi, Tugas dan Fungsi, serta Tata Kerja Dinas Perpustakaan dan Kearsipan, Dinas Perpustakaan dan Kearsipan mempunyai tugas membantu Bupati melaksanakan urusan pemerintahan dan tugas pembantuan di bidang perpustakaan dan bidang kearsipan.

Dinas Perpustakaan dan Kearsipan dalam melaksanakan tugas mempunyai fungsi: 1) penyusunan rencana kerja Dinas Perpustakaan dan Kearsipan; 2) perumusan kebijakan teknis urusan pemerintahan bidang perpustakaan dan urusan pemerintahan bidang kearsipan; 3) pelaksanaan, pelayanan, dan pembinaan urusan pemerintahan bidang perpustakaan dan urusan pemerintahan bidang kearsipan; 4) evaluasi dan pelaporan pelaksanaan urusan pemerintahan 
bidang perpustakaan dan urusan pemerintahan bidang kearsipan; 5) pelaksanaan kesekretariatan dinas; dan 6) pelaksanaan tugas lain yang diberikan oleh Bupati sesuai tugas dan fungsinya dan/atau sesuai ketentuan peraturan perundangundangan.

\section{Pengolahan Arsip Statis di DPK Kabupaten Sleman}

Berdasarkan UU Nomor 43 Tahun 2009 tentang Kearsipan, pengelolaan arsip statis di daerah yang wajib dikelola oleh lembaga kearsipan daerah kabupaten adalah arsip statis yang berasal dari Organisasi Pemerintah Daerah, Pemerintah Desa, BUMD, perorangan, organisasi masyarakat dan organisasi politik. Pengelolaan arsip statis diawali dari kegiatan penilaian, akuisisi, pengolahan, pelestarian, publikasi dan akses layanan.

Lembaga kearsipan daerah wajib menjamin kemudahan akses arsip statis bagi kepentingan pengguna arsip. Agar arsip dapat diakses, arsip harus diolah dahulu sehingga dapat meghasilkan sarana temu kembali arsip berupa daftar arisp statis (DAS), inventaris arsip, guide khasanah, dan guide tematik.

\section{Daftar Arsip Statis (DAS)}

Daftar arsip statis merupakan sarana penemuan kembali arsip yang belum lengkap dengan kebuktian terciptanya arsip berupa sejarah lembaga pencipta arsip dan sejarah arsip. Daftar arsip statis yang disusun oleh DPK Kabupaten Sleman antara lain:

a. DAS Dinas Bina Marga Kabupaten Daerah Tingkat II Sleman. Daftar ini berisi arsip-arsip proyek APBD Dinas Bina Marga seperti perencanaan teknis dan leger jalan, pembangunan jalan, peningkatan jalan, pemeliharaan jalan, pemeliharaan jembatan, serta pemanfaatan dan perijinan jalan.

b. DAS Dinas Pengairan Kabupaten Daerah Tingkat II Sleman

c. DAS Dinas Pekerjaan Umum Kabupaten Daerah Tingkat II Sleman. Daftar ini berisi arsip-arsip tentang penelitian tentang hasil pekerjaan proyek, perencanaan proyek-proyek APBD, pembangunan jalan dan jembatan, pembangunan gedung-gedung, proyek penyehatan lingkungan pemukiman, perencanaan umum tata ruang kota, dan sebagainya.

d. DAS Sekretariat DPRD Kabupaten Sleman. Daftar ini berisi arsip-arsip tentang paripurna DPRD pembahasan Perda SOTK Kabupaten Sleman, pembahasan Perda Lambang Daerah Kabupaten Sleman, proses pemilihan dan pelantikan bupati dan wakil bupati periode 2005-2010,

e. Daftar Arsip Statis Gempa Bumi Tahun 2006, berisi arsip tentang peristiwa gempa bumi yang terjadi pada 26 Mei 2006 akuisisi dari beberapa Perangkat daerah maupun Pemerintah Desa seperti Bappeda, Dinas Sumber Daya Air, Energi, dan Mineral, Dinas Tenaga Kerja dan Sosial, Dinas Pengelolaan Keuangan dan Aset Daerah, RSUD Sleman, beberapa kecamatan seperti Kecamatan Berbah, Prambanan, Depok, Gamping, Godean, Mlati, Moyudan, Ngaglik, Sleman, Turi, Pemerintah Desa 
Ambarketawang, Gamping, Balecatur Gamping, Bokoharjo Prambanan, Kalitirto Berbah, Nogotirto Gamping, Sendangtirto Berbah, Sidokarto Godean, Sumberharjo Prambanan, Tegaltirto Berbah, Tlogoadi Mlati, SUmberadi Mlati, Sendangrejo Minggir yang didalamnya memuat tentang data rumah rusak baik rusak berat, sedang, dan ringan, rekapitulasi penerimaan pokmas, data pembangunan rumah rusak, penyaluran dan penerimaan bantuan barang, dan sebagainya.

f. Daftar Arsip Statis Pemilu (Pileg, Pilpres, Pilkada) Tahun 2004 - 2014, berisi arsiparsip akuisisi dari KPU Kabupaten Sleman seperti Pemilihan Legislatif tahun 2009, pemilihan kepala daerah dan wakil kepala daerah tahun 2005, 2010, pemilihan presiden dan wakil presiden tahun 2009

g. DAS Panitia Pengawas Pemilu Kabupaten, berisi arsip-arsip kegiatan Panswaskab untuk pemilu tahun 2014

h. DAS Kartografi Dinas Cipta Karya Tahun 1964-2002, berisi arsip-arsip peta akuisisi dari Dinas Cipta Karya seperti peta jaringan jalan dan air, peta tanah Sendangtirto (lapangan udara Adi Sutjipto), peta rencana detail tata ruang, peta wilayah administrasi dan sebagainya.

i. DAS Kearsitekturan Dinas Cipta Karya Tahun 1987-1997, berisi arsip-arsip dari Dinas Cipta Karya seperti peta masjid Agung Sleman, peta gedung DPRD SLeman, Wisma Kaliurang, Wisma
Pemda, GOR, Terminal Jombor, master plan kota pemerintahan Kabupaten Sleman

j. DAS Mantan Bupati Sleman, berisi arsiparsip personal file mantan Bupati Sleman seperti Drs. Samirin dan Drs. Arifil Ilyas mulai dari akte lahiran, perjalanan karir, serta penghargaan yang pernah diraih.

k. DAS Satkorlak Kabupaten Sleman, berisi arsip-arsip Satkorlak pada saat peristiwa Gempa Bumi 27 Mei 2006 seperti pendataan rumah akibat gempa baik itu rumah rusak berat, sedang, maupun ringan, daftar korban bencana alam, data pengungsi, dan sebagainya.

1. DAS SOTK (Struktur Organisasi dan Tata Kerja) Kabupaten Sleman, berisi arsip-arsip SOTK lama seperti Kantor Pembantu Bupati, Sekretariat Wilayah Daerah Tingkat II, Dinas Pendapatan Daerah, BP7, dan sebagainya

m. DAS Kearsitekturan Gedung Sekretariat Daerah Kabupaten Sleman

n. DAS Kearsitekturan Rumah Dinas Bupati Sleman

o. DAS G30 S PKI, berisi arsip-arsip laporan kegiatan pembinaan OT (Organisasi Terlarang) di berbagai kecamatan di wilayah Kabupaten Sleman

p. DAS Hari Jadi Kabupaten Sleman, mulai dari pembentukan panitia penentu hari jadi kabupaten Sleman, penetapan hari jadi Kabupaten Sleman, hingga muncul Peraturan Daerah Kabupaten Daerah Tingkat II Sleman No 12 Tahun 1998 tentang Hari Jadi Kabupaten Sleman

q. DAS Foto kegiatan Pemkab Sleman 
Akuisisi dari Bagian Humas

1) Foto pelantikan Bupati Sleman Samirin dan kegiatannya

2) Foto pelantikan Bupati dan Wakil BUpati periode 2000-2005

3) Foto hitam putih dan berwarna kegiatan mantan Bupati Sleman KRT Prodjo Sujoto

4) Foto kegiatan tahun 1980-1990an seperti foto pencanangan bulan bakti LKMD, Lomba Cerdas Tangkas Terpadu, Penataran Jupen, Pameran $\mathrm{P}$ e $\mathrm{mb}$ a $\mathrm{g} u \mathrm{n}$ a,$\quad \mathrm{L} \mathrm{o} \mathrm{m} \mathrm{b}$ a Kelompencapir, festival kesenian tradisional, peresmian terminal Jombor, foto gedung-gedung Pemda lama, pelantikan Bupati Sleman Arifin Ilyas, upacara tradisional Saparan, penataran P4 Pola Terpadu, penataran P4 pola pendukung 25 jam, proyek pembangunan desa, proyek jalan desa, Gerakan Displin Nasional (GDN), foto peringatan Hari Jadi Kabupaten Sleman, foto berkaitan dengan transportasi, infrastruktur, industri, pasar tradisional, pariwisata, aktivitas jual beli tempo dulu, permainan tradisional tempo dulu, kesenian tradisional tempo dulu, upacara adat, budaya perilaku tempo dulu,

\section{Inventaris Arsip}

Selain DAS, DPK Kabupaten Sleman juga menyusun Inventaris Arsip. Inventaris arsip yang disusun oleh DPK Kabupaten Sleman antara lain:
a. Inventaris Arsip KP3M Tahun 2010 - 2014

b. Inventaris Arsip Gempa Bumi Tahun 2006

c. Inventaris Arsip Departemen Penerangan Tahun 1975 - 2000, berisi tentang arsip data gedung Kantor Deppen, data tanah Kantor Deppen, pembinaan penerangan kecamatan,

d. Inventaris Arsip Dinas Cipta Karya Tahun 1995

e. Inventaris Arsip SOTK Tahun 1971 2011

f. Inventaris Arsip Kartografi Dinas Cipta Karya Tahun 1964-2002

g. Inventaris Arsip Kearsitekturan Dinas Cipta Karya Tahun 1987-1997

h. Inventaris Arsip Dinas Kimpraswilhub

i. Inventaris Arsip Dinas Bina Marga

j. Inventaris Arsip Dinas Pengairan

\section{Guide Arsip Statis}

Guide arsip yang telah dimiliki oleh DPK Kabupaten Sleman antara lain:

a. Guide Arsip Statis Khasanah Arsip Lembaga Pemerintah Kabupaten Sleman Yang dilikuidasi Tahun 1975-2014

b. Guide Arsip Statis Khasanah Arsip Gempa Bumi Tahun 2006

Selain DAS, inventaris, dan Guide, DPK Kabupaten Sleman juga melakukan penelusuran arsip dan wawancara sejarah lisan. Penelusuran arsip mantan Bupati Sleman dan mantan pejabat eselon II yang dimiliki oleh DPK Kabupaten Sleman antara lain:

1. penelusuran mantan Bupati Sleman Samirin

2. Penelusuran mantan Bupati Sleman Drs. Arifin Ilyas

3. Penelusuran mantan Sekda Sleman RM. Tirun Marwito 
4. Penelusuran mantan Sekda Sleman Sunartono

5. Penelusuran mantan-mantan Kepala Dinas

6. Penelusuran mantan Ketua DPRD Kabupaten Sleman (Kamil Sugema, Rendradi, dll)

Penelusuran arsip tokoh budaya Sleman yang dimiliki oleh DPK Kabupaten Sleman antara lain:

1. Tokoh pelukis internasional Affandi

2. Tokoh pelukis internasional Kartika Affandi

3. Tokoh pembuat keris Empu Djeno

4. Tokoh kethoprak Gito-Gati

5. Tokoh Pesinden Nyi Tjondro Lukito

6. Tokoh Pesinden Rubinem

Selain tokoh budaya, tokoh-tokoh di bidang lain yang berhasil ditelusuri dan dimiliki oleh DPK Kabupaten Sleman antara lain

1. Tokoh Pengusaha Ayam Saliman Ibu Suciati

2. Tokoh Pengusaha Kuliner Jejamuran Bapak Ratidjo

3. Tokoh Mantan Atlit Bulutangkis Finarsih

Wawancara sejarah lisan yang telah berhasil dilakukan dan dimiliki oleh DPK Kabupaten Sleman antara lain:

1. Wawancara sejarah lisan dengan Arkeolog Prof. Dr. Timbul Haryono, M.Sc

2. Wawancara sejarah lisan dengan Sejarawan Prof. Dr. Joko Suryo, MA

3. Wawancara sejarah lisan dengan mantan Sekda Sleman RM Tirun Marwito, S.H.

Kegiatan penduplikatan arsip yang berhasil dilakukan dan dimiliki oleh DPK Kabupaten Sleman antara lain:

1. Penduplikatan arsip tentang peristiwa tanah di Kecamatan Minggir tahun 1957

2. Penduplikatan arsip tentang SOTK Kabupaten Sleman yang telah dilikuidasi atau berubah nomenklatur
3. Penduplikatan arsip batas wilayah Kabupaten Sleman dengan Kabupaten Magelang, Kabupaten Klaten, Kota Yogyakarta, Kabupaten Kulonprogo, dan Kabupaten Bantul.

4. Penduplikatan arsip perjanjian kerjasama tentang pendirian lapangan golf yang berada di Cangkringan

\section{Layanan Akses Arsip Statis}

Lembaga kearsipan daerah semestinya tidak hanya sekedar menyimpan atau merawat arsip statis saja, namun juga mampu mengolah dan menyajikan arsip statis tersebut menjadi sebuah informasi yang dapat dimanfaatkan oleh masyarakat. Pemanfaatan arsip statis dapat dilakukan melalui publikasi dan layanan arsip. Publikasi arsip yang telah dilaksanakan oleh Dinas Perpustakaan dan Kearsipan (DPK) Kabupaten Sleman adalah pelaksanan pameran kearsipan serta penerbitan bulletin arsip. Dengan pelaksanaan pameran kearsipan dan penerbitan bulletin arsip, maka pemasyarakatan kearsipan terhadap khasanah arsip yang dimiliki serta penyelenggaraan kearsipan oleh DPK Kabupaten Sleman dapat tersampaikan sehingga fungsi lembaga kearsipan daerah sebagai penyelenggara layanan publik khususnya publikasi arsip statis dapat bermanfaat bagi masyarakat luas.

Arsip statis yang telah diolah oleh DPK Kabupaten Sleman kemudian disimpan dalam sarana penyimpanan arsip. Dalam rangka pendayagunaan arsip bagi masyarakat, DPK memberikan kesempatan yang luas bagi masyarakat untuk mengakses arsip. Akses arsip yang dimaksud adalah peminjaman arsip. 
Adapun prosedur akses arsip berupa peminjaman dapat divisualisasikan melalui bagan berikut:

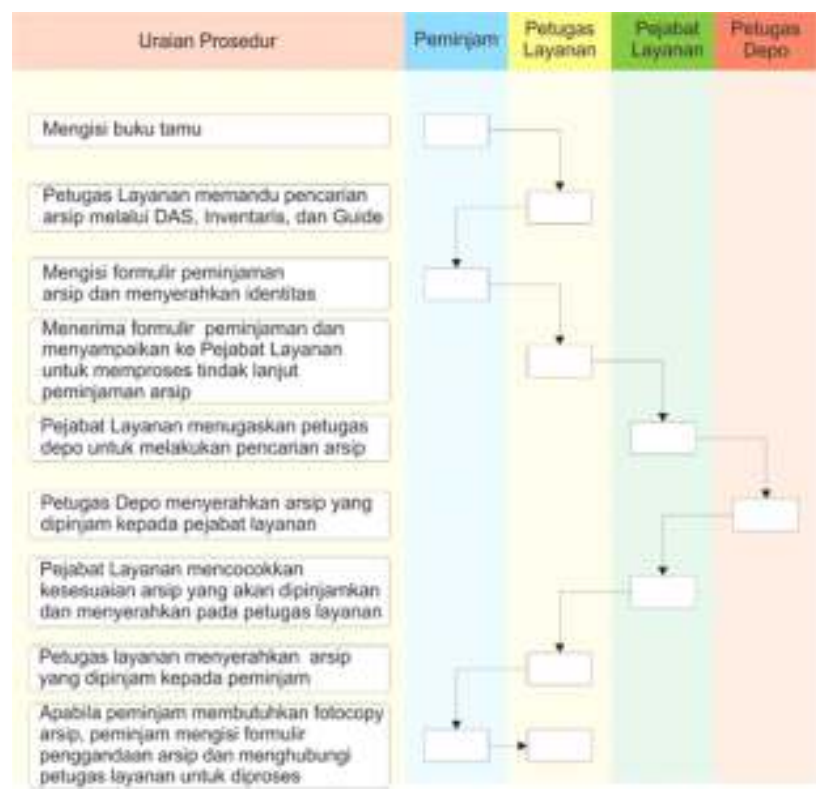

Gambar 2. Prosedur Peminjaman Arsip

Dalam setahun terakhir, masyarakat mulai mengakses arsip statis yang dioleh oleh Dinas Perpustakaan dan Kearsipan Kabupaten Sleman untuk berbagai keperluan. Berikut adalah data akses selama tahun 2018:

\begin{tabular}{|c|l|c|}
\hline No & \multicolumn{1}{|c|}{ Keperluan } & $\begin{array}{c}\text { Jumlah } \\
\text { pengakses }\end{array}$ \\
\hline 1 & Tugas perkuliahan & 19 \\
\hline 2 & Penyusunan tugas akhir skripsi & 4 \\
\hline 3 & $\begin{array}{l}\text { Pemberdayaan masyarakat } \\
\text { desa }\end{array}$ & 3 \\
\hline 4 & Penelitian & 1 \\
\hline 5 & Keperluan tamu & 14 \\
\hline 6 & Kegiatan perlombaan & 1 \\
\hline 7 & $\begin{array}{l}\text { Keperluan izin mendirikan } \\
\text { bangunan Jumlah }\end{array}$ & 4 \\
\hline & \multicolumn{1}{|c|}{} \\
\hline
\end{tabular}

Tabel 2. Data akses arsip statis

Dinas Perpustakaan dan Kearsipan Kabupaten Sleman tahun 2018

Sumber: Laporan Akses Arsip Statis
Atas capaian dalam pelaksanaan berbagai program kerja, termasuk dalam pengolahan dan layanan akses, Dinas Perpustakaan dan Kearsipan yang saat itu bernama Kantor Arsip Daerah (KAD) Kabupaten Sleman diikutsertakan dalam kegiatan akreditasi kearsipan yang dilaksanakan oleh Arsip Nasional Republik Indonesia (ANRI) pada tahun 2016. Kegiatan ini dibiayai dengan dana DIPA ANRI. KAD Kabupaten Seman merupakan lembaga kearsipan daerah tingkat kabupaten pertama yang mendapatkan kesempatan mengikuti akreditasi kearsipan dari Arsip Nasional Republik Indonesia (ANRI). Pada kesempatan tersebut peserta akreditasi kearsipan lainnya adalah adalah Provinsi Kalimantan Timur, Provinsi Kalimantan Barat, Provinsi Sumatera Barat, dan Provinsi DKI Jakarta.

Rangkaian kegiatan akreditasi tersebut dilaksanakan selama kurang lebih 5 bulan yang dimulai sejak bulan Mei hingga Oktober 2016. Adapun rangkaian kegiatannya berupa sosialisasi, pengisian instrumen dan melengkapi portofolio, verifikasi lapangan, uji petik, rekomendasi, sidang pleno di depan majelis Pertimbangan Akreditasi Kearsipan dan penetapan hasil akreditasi kearsipan. Pemaparan akreditasi kearsipan dilaksanakan pada tanggal 3 Oktober 2016 di depan Majelis Pertimbangan Akreditasi Kearsipan.

KAD Kabupaten Sleman dalam penilaian akreditasi ini memperoleh predikat penilaian sangat baik (akreditasi A) dengan nilai 86,47. Penyerahan penghargaan akreditasi ini dilaksanakan di Pendopo Rumah Dinas Bupati Sleman pada hari Rabu, tanggal 16 November 2016 dan diserahkan langsung oleh Kepala ANRI 
Dr. Mustari Irawan, MPA kepada Pemerintah Kabupaten Sleman yang diwakili oleh Drs. Iswoyo Hadiwarno selaku Penjabat Sekda Kabupaten Sleman.

\section{KESIMPULAN}

Khazanah arsip statis yang dimiliki oleh Dinas Perpustakaan dan Kearsipan Daerah Kabupaten Sleman telah diolah sesuai dengan prosedur operasional standar. Kurang lebih sebanyak 30\% dari jumlah arsip telah diolah. Sisanya dalam tahap verifikasi. Arsip yang diolah cukup beragam dari segi usia penciptaan. Tercatat arsip tertua yaitu tentang Gatsu 2605 (tercipta sekitar tahun 1945) dan tentang peristiwa tanah di Kecamatan Minggir, serta tentang Jogjakarta Koorei Angka 1 tentang Peroebahan Atoeran dan Soesoenan Pemerintah Kesoeltanan Jogjakarta (Jogjakarta Koosetyoo).

Hasil dari pengolahan arsip statis adalah sarana temu kembali arsip berupa daftar arsip statis, inventaris, dan guide arsip. Berbagai sarana temu kembali tersebut diharapkan dapat membantu user dalam pemanfaatan arsip dalam berbagai keperluan.

Sebagai sebuah upaya, pengolahan dan layanan arsip statis seharusnya mendapatkan apresiasi yang baik. Namun pemanfaatan arsip oleh masyarakat belum optimal karena perhatian masyarakat terhadap arsip belum tinggi. Pada tahun 2016, baru tercatat akses sebanyak 35 berkas; pada 2017 sebanyak 42 berkas; dan pada 2018 sebanyak 46 berkas. Oleh karena itu penulis menyarankan agar dilaksanakan publikasi arsip yang lebih banyak dan menjangkau berbagai lapisan masyarakat, seperti kegiatan pameran, pembuatan film dokumenter, dan penerbitan naskah sumber arsip.

\section{DAFTAR PUSTAKA}

Cohen, L., Manion, L., \& Morrison, K, 2007, Research Methods in Education, London and Newyork: Routledge

Cook, Terry, 2013, Evidence, memory, identity, and community: four shifting archival paradigms. Archival Science, 13, 95120

Deliarnoor, N.A., 2007, Aspek Hukum dalam Kearsipan. Jakarta: Universitas Terbuka.

Greene, Mark A., 2009, The Power of Archives: Archivists' Values and Value in the Postmodern Age, The American Archivists, 72, 17-41

Griffin, Andrew, dkk., 2009. Glosary of Terms. London: International Records Management Trust.

Hitchcock, G. and Hughes, D., 1995, Research and the Teacher (second edition). London: Routledge

Idrus, Muhammad., 2009, Metode Penelitian Ilmu Sosial; Pendekatan Kualitatif dan Kuantitatif (Edisi Kedua). Yogyakarta: Universitas Islam Indonesia.

Kirchhoff, T., Schweibenz, W., dan Sieglerschmidt, J. 2008. "Archives, Libraries, Museums and the Spell of Ubiquitous Knowledge", Archival Science, 8, 251-266

Nazir, Moh., 2017, Metode Penelitian, Bogor: Ghalia Indonesia

Pearce-Moses, R., 2005, A Glosary of Archival and records Therminology, Chicago: Society of American Archivists

Peraturan Pemerintah nomor 28 tahun 2012 
tentang Pelaksanaan Undang-undang nomor 43 tahun 2009 tentang Kearsipan

Rhee, Hea Lim ., 2015, Reflections on Archival User Studies. American Library Association. 54(4), 29-42

Schwartz, J.M And Cook, Terry., 2002, "Archives, Records, and Power: The Making of Modern Memory", Archival Science. 2. 1-19

Stewart, C., 2012, Preservation and Access I an Age of E-Science and Electronic Records: Sahring the Problem and Discovering Common Sollutions. Journal of Library Administration, 96:7-4. 265-278
Undang-undang nomor 43 tahun 2009 tentang Kearsipan

Waard, A.D., Hierarchy of Data, diakses dari https://libraries.mit.edu/news/maslowshierarchy-for-data/pada 10 Januari 2019. 